Proceedings

\title{
Individualized dietary supplements enriched with microbial propionic acid for athletes and elderly with benefits on gut microbiota ${ }^{\dagger}$
}

\author{
Monica Trif ${ }^{1 *}$, Ann-Kristin Schwarze ${ }^{2}$, Malte Bethke ${ }^{3}$, Berta Alvarez Penedo ${ }^{2}$ and Alexandru \\ $\operatorname{Rusu}^{2, *}$ \\ 1 Department of Food Research, Centiv GmbH, 28857 Syke, Germany; \\ 2 Biozoon Food Innovations $\mathrm{GmbH}, 27572$ Bremerhaven, Germany; \\ 3 Department of Process Technology, Centiv GmbH, 28857 Syke, Germany \\ * Correspondence: monica trif@hotmail.com; rusu@biozoon.de \\ + Presented at the 1st International Electronic Conference on Microbiology, 2-30 November 2020; Available \\ online: https://ecm2020.sciforum.net/
}

Published: 2 November 2020

\begin{abstract}
Personalized dietary supplements adapted to the individual needs of athletes and elderly enriched with microbial propionic acid are produced in form of a powder, ready to be mixed in drinks such as orang juices. Recent studies shown that fresh and pasteurized orange juices have a positive influence on gut microbiota, exhibit selective prebiotic activity, particularly in terms of gut microbiota, by increasing Lactobacillus spp., Enterococcus spp., Bifidobacterium spp., and Clostridium spp., and reducing Enterobacteria. Besides, studies have been reported the effect of the combined use of probiotics and organic salts, such as propionic acid salts, on the in vitro inhibition of microorganisms. On the other side, the short chain fatty acid propionic acid influences the gutmediated immune regulation of people, and reduce lipogenesis and inhibit serum cholesterol synthesis.
\end{abstract}

Keywords: personalisation; nutrition; propionic acid; athletes; elderly

\section{Introduction}

Nutritional requirements are required for human health, and the research is still ongoing to describe their function at the cellular and molecular level [1].

The diet influences the composition and activity of the microbiota - and this is more important for health than long assumed. Microbiota research over the past ten years has provided insights into the mechanisms. A typical western diet rich in fat and protein, with lots of meat and fast food, stimulates the growth of bacteria that contain lipopolysaccharides in their cell membrane. These in turn promote inflammation and destabilize the intestinal barrier. Fiber is the key to a healthy microbiota [2].

Depending on the state of health, dysbiosis can also occur in old age. Fragility, inflammation and malnutrition lead to unfavorable changes in the microbiota. The number and diversity of bacterial strains decrease, the main strains shift in favor of pathobionts, and at the expense of protective anaerobes. The main cause is probably a one-sided diet with less fiber and micronutrients. Healthy seniors, on the other hand, have a stable intestinal microbiota up to the age of 80 . However, the immune system ages in everyone, whether frail or not. At the same time, the susceptibility to infection increases and inflaming occurs - a chronic, subclinical inflammation. In every second senior, the inflammation parameters such as C-reactive protein (CRP) are slightly increased, which is associated with an increased risk of cardiovascular events such as heart attack and stroke. In addition, folic acid and vitamin B12 levels decrease with age [3]. 
Propionic acid, together with acetic acid and butyric acid are the most abundant short chain fatty acids (SCFA), representing $90-95 \%$ of the SCFA present in the colon. SCFA as postbiotics, have distinct physiological effects as contribute to shaping the gut environment and influence the physiology of the colon. SCFA can be used as energy sources by host cells and the intestinal microbiota [4-6].

Food-grade propionic acid (E280) can be used as a preservative in food as well, and listed in Commission Regulation (EU) No 231/2012 as an authorized food additive and categorized in "Additives other than colors and sweeteners". Can be used to produce its salts: sodium propionate (E281), calcium propionate (E282) and potassium propionate (E283), with the maximum permitted levels (MPLs) from 1000 to $3000 \mathrm{mg} / \mathrm{kg}$ in foods $[7,8]$.

Recent studies shown that fresh and pasteurized orange juices have a positive influence on gut microbiota, exhibit selective prebiotic activity, particularly in terms of gut microbiota, by increasing Lactobacillus spp., Enterococcus spp., Bifidobacterium spp., and Clostridium spp., and reducing Enterobacteria. Due to its nutrients, orange juice is at least as healthy as the numerous trend smoothies, keeps us mentally fit and is also cheape [9].

A new study by the renowned Harvard University has now even shown that orange juice can prevent dementia. Regular consumption of orange juice increased the efficiency of the brain in 47 percent of the study participants. The reason is the high proportion of antioxidants and other nutrients that have a preventive effect against dementia. Those who drink orange juice every day can protect themselves from the molecules that cause dementia. Regular consumption of the fruit juice is important for its effectiveness, therefore in subjects who only drank orange juice once a month, the drink had no beneficial effects on the brain. Orange juice, with immune system-boosting vitamin $C$ and phytonutrients, is not a muscle building substance per se, but in certain situations the can work wonders - especially after training and in the right combination. Earlier studies, provided evidence of an immune-modulating effect of prebiotics and postbiotics in athletes and elderly people. [10]

\section{Materials and Methods}

The microbial propionic acid is produced from lignocellulosic biomass, in form of a powder, free or encapsulated as presented in a previous study [11-13]. Personalized dietary supplements (containing fibers, minerals and vitamins) adapted to the individual needs of athletes and elderly has been developed in previous research projects [14-16]. Fresh and pasteurized orange juices purchased commercially.

\section{Results}

The objective was the preparation of novel fruit beverage product fortified with dietary fibres (soluble fibres), macro- and micronutrients using the microbial propionic acid, which has been produced in form of a powder (free and encapsulated). Novelty liquid food beverage product has been tested to evaluate its sensory. Great solubility and free of color powder, and no odour and taste or modified consistency noticed when incorporated microbial propionic acid as $0.1 \mathrm{~g} / \mathrm{L}$ to serve as postbiotic in the final product.

Further chemical properties to check their quality and safety during storage and to evaluate stability of used functional compounds will be done.

\section{Conclusions}

The results support the current trend in the development of feasible, sustainable or futureoriented nutritional concepts and provides the basis for conscious eating behavior.

Funding: The research leading to these results has received funding from the Federal Ministry of Education and Research (BMBF) Germany, program no. 031B0091, “BIORAFFINERIE 2021”, and grant agreement No. 031B0660, "ELBE-NH", and from the European Union's Horizon 2020 research and innovation programme under grant agreement No. 816303 (STANCE4HEALTH).

Conflicts of Interest: “The authors declare no conflict of interest." 


\section{References}

1. Rusu, A., Alvarez Penedo, B.. Schwarze, A-K., Trif, M. The impact of Candida spp. on physiological alterations in gut microbiota. Candida elimination diet therapy. Candidiasis (2020b). Edited by Prof. Tulin Askun and Dr. Juliana Simoni Moraes Tondolo. Publisher: IntechOpen ISBN: 978-1-83881-112-9

2. Rusu, A.; Randriambelonoro, M.; Perrin, C.; Valk, C.; Alvarez, B.; Schwarze, A.-K. Aspects Influencing Food Intake and Approaches towards Personalising Nutrition in the Elderly. J. Popul. Ageing 2020,118,doi:10.1007/s12062-019-09259-1.

3. Forstner, S.; Rusu, A. Development of personalised food for the nutrition of elderly consumers. In Know Your Food: Food Ethics and Innovation; Wageningen Academic Publishers, S.: Wageningen, The Netherlands, 2015;pp.24-27

4. Ríos-Covián, D.; Ruas-Madiedo, P.; Margolles, A.; Gueimonde, M.; de Los Reyes-Gavilán, C.G.; Salazar, N. Intestinal Short Chain Fatty Acids and their Link with Diet and Human Health. Front Microbiol. 2016; 7:185.

5. Parada Venegas, D.; De la Fuente, M.K.; Landskron, G.; González, M.J.; Quera, R.; Dijkstra, G.; Harmsen, H.J.M.; Faber, K.N. and Hermoso, M.A. Short Chain Fatty Acids (SCFAs)-Mediated Gut Epithelial and Immune Regulation and Its Relevance for Inflammatory Bowel Diseases. 2019. Front. Immunol. 10:277.

6. Hosseini, E.; Grootaert, C.; Verstraete, W.; Van de Wiele, T. Propionate as a health-promoting microbial metabolite in the human gut. Nutrition Reviews. 2011, 69 (5), 245-258

7. Commission Regulation (EU) No 1129/2011 of 11 November 2011 amending Annex II to Regulation (EC) No 1333/2008 of the European Parliament and of the Council by establishing a Union list of food additives, https:/eur-lex.europa.eu/legal-content/EN/TXT/?uri=CELEX:02011R1129-20131121

8. Scientific Opinion on the re-evaluation of propionic acid (E 280), sodium propionate (E 281), calcium propionate (E 282) and potassium propionate (E 283) as food additives, EFSA, 2014, https://efsa.onlinelibrary.wiley.com/doi/epdf/10.2903/j.efsa.2014.3779

9. Ana Luiza Katia Sivieri, A.L. An exploratory study on the influence of orange juice on gut microbiota using a dynamic colonic model. Food Research International. 2016, 84, 160-169

10. Pereira-Caro, G.; Polyviou, T.; A Ludwig, I.; Nastase, A.M.; Moreno-Rojas, J.M.; Garcia, A.L.; Malkova, D.; Crozier, A. Bioavailability of orange juice (poly)phenols: the impact of short-term cessation of training by male endurance athletes, The American Journal of Clinical Nutrition, 2017, 106 ( 3), 791-800

11. Trif, M.; Schwarze, A.-K.; Penedo, B.A.; Bethke, M.; Rusu, A.V. Encapsulated Microbial Propionic Acid as Additive for Texture-Defined Bread. Mater. Proc. 2020, 2, 2.

12. Available online: https://www.tuhh.de/v8/research/elbe-nh.html (accessed on 10 October 2020).

13. Available online: https://www.tuhh.de/v8/prof-smirnova/forschungsthemen/thermisch-enzymatischehydrolyse.html (accessed on 10 October 2020).

14. Rusu, A.; Alvarez, B.; Bethke, M.; Schwarze, A.K.; Trif, M. SMART TECHNOLOGIES FOR PERSONALIZED NUTRITION AND CONSUMER ENGAGEMENT (STANCE4HEALTH EU H2020FUNDED PROJECT). Bull. UASVM Food Sci. Technol. 2020, 77,97-100.

15. Trif, M.; Muresan, L.; Bethke, M. Personalised nutritional powder for elderly developedinoptifeleuropeanproject. Bull. UASVM Food Sci. Technol. 2016, 73,149-150

16. Bethke, M.; Muresan, L.; Trif, M. OPTIFEL Personalized Calculator. Bull. UASVM Food Sci. Technol. 2016,73, 151-152

Publisher's Note: MDPI stays neutral with regard to jurisdictional claims in published maps and institutional affiliations.

(C) 2020 by the authors. Submitted for possible open access publication under the terms and conditions of the Creative Commons Attribution (CC BY) license (http://creativecommons.org/licenses/by/4.0/). 